\title{
Os direitos invisíveis*
}

Claudia Asazu

A fala tranqüila da subprocuradorageral da República e Procuradora Federal dos Direitos do Cidadão, Ela Wiecko Volkmer de Castilho, esconde uma grande inquietação quando o assunto é a defesa dos direitos culturais. "Quando se pensa em direitos culturais, logo se associa a minorias étnicas, populações tradicionais ou em obras de arte e tradições folclóricas. Mas esse patrimônio cultural, que não tem a grandiosidade de um monumento ou o grau de elaboração de um livro, aquela coisa do dia-dia, das relações pessoais que se estabelecem em determinado grupo ou comunidade, que é também um patrimônio cultural, não tem força", afirma. Ela faz um alerta: "na prática, os direitos culturais são invisíveis, o que leva a violações sistemáticas a este se a outros direitos humanos".

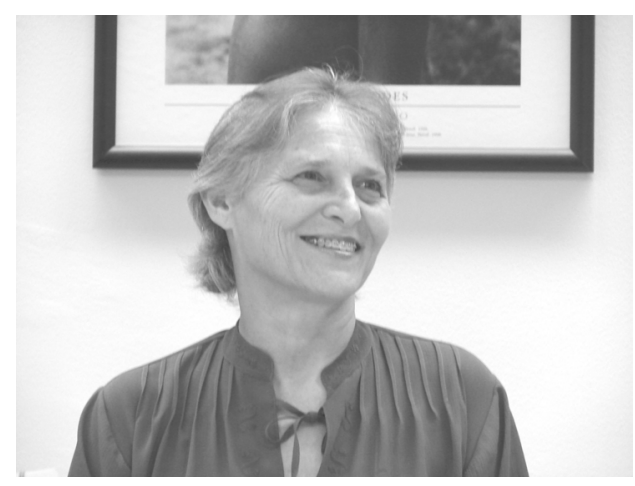

Ela Wiecko - Procuradora Federal dos Direitos do Cidadão
$\mathrm{Na}$ Procuradoria Federal dos Direitos do Cidadão, que coordena as atividades dos procuradores da cidadania em todo o País nas questões relacionadas aos direitos constitucionais da pessoa humana, onde Ela Wiecko está desde 2004, o tema é muito presente. Chegam ao seu gabinete, diariamente, mais de 40 processos, grande parte dos quais se refere às prestações dos serviços de educação, saúde e previdência. "E vemos que muitos desses conflitos têm origem na falta de habilidade do gestor público de conversar com o cidadão", ressalta.

A procuradora foi, durante quatro anos, coordenadora da $6^{a}$ Câmara de Coordenação e Revisão do Ministério Público Federal, que trata dos temas relativos aos indígenas e outras minorias, em particular quilombolas, comunidades extrativistas, ribeirinhas e ciganos. Essa experiência reforça sua constatação de que o desrespeito aos direitos culturais atinge não somente as chamadas "minorias" e que a preocupação em defendê-los deve ser expandida a toda sociedade. "Os direitos culturais constituem, a meu ver, o elementochave para que as políticas públicas direcionadas a atender os direitos econômicos e sociais sejam bem sucedidas", afirma. A seguir, leia os principais trechos da entrevista. 


\section{Respeito às diferenças}

"A essência dos direitos culturais é o respeito aos modos de vida. No interior do País, por exemplo, as pessoas saem à noite e ficam sentadas nos bancos e calçadas. Isso é uma manifestação da cultura do interior do Brasil e tem de ser respeitada. Em geral, entretanto, verifica-se, de início, desconsideração dessa cultura popular por parte dos servidores públicos e das políticas públicas. Pressupõe-se que a cultura que vale a pena ser protegida é aquela que resulta em alguma produção material. $\mathrm{O}$ discurso é 'eles são pobres, podem melhorar de vida com a mudança, melhorar o sistema de troca'. Um exemplo: há uma comissão, no âmbito do Conselho de Defesa dos Direitos da Pessoa Humana, que levanta os casos de construção de barragens que tenham resultado em violação de direitos humanos para proposta de encaminhamento de procedimentos que estabeleçam uma rotina de não violação desses direitos. Basicamente, essas violações referem-se à degradação ambiental e à desestruturação causada pela construção desse tipo de obra. São pessoas que perderam seu espaço de encontro, não podem mais recorrer ao seu modo de produção, ao seu jeito de cultivar a terra. O empreendedor diz: 'antes vocês moravam em uma casa de sapé ou de barro

\section{Avanços na Constituição não se refletem na prática jurídica}

Em "Processo civil e igualdade étnico-racial" (PIOvesan, Flávia; SouZA, Douglas Martins de (coord.). Ordem jurídica e igualdade étnico-racial. Brasília: SEPPIR, 2006), Ela Wiecko aponta a mudança de paradigma na relação entre Estado, sociedade e as minorias a partir da Constituição de 1988, expresso particularmente nos artigos 215 e 216, pelos quais a idéia de incorporar grupos divergentes em prol da construção de uma comunhão nacional dá lugar à idéia de um Estado pluriétnico. A Constituição determina que cabe ao Estado o dever de garantir a todos o pleno exercício de seus direitos culturais - ou seja, garantir o respeito às formas de expressão e aos modos de criar, fazer e viver. No entanto, esse avanço constitucional, segundo a autora, não foi acompanhado pela legislação infraconstitucional.

Exemplo disso é a inadequação do Código de Processo Civil para a tutela dos chamados direitos transindividuais, ou seja, que têm como titular o grupo como um todo. A lacuna é particularmente visível no caso dos direitos culturais. A lei da Ação Civil Pública (Lei no 7.347/85) buscou preenchê-la, possibilitando que grupos organizados em forma de associações postulem a fixação de responsabilidade por danos causados ao meio ambiente, ao consumidor, aos bens de valor artístico, estético, histórico, turístico, paisagístico e urbanístico, bem como à ordem econômica e à economia popular. Wiecko ressalta, entretanto, que essa possibilidade não é conferida às comunidades indígenas, quilombolas e ciganas, que não têm legitimidade para propor essa ação. "A criação de associações, a utilização de outras espécies de ações, a propositura da ação pelo Ministério Público ou por outras entidades são soluções adotadas, que, contudo, não reforçam a autonomia dos povos e comunidades", afirma. Não existindo no Código de Processo Civil vigente a possibilidade de ajuizar um processo civil coletivo, essas comunidades ficam, a despeito do preceito constitucional, à margem da proteção jurídica. Outra lacuna referese à ausência de um "tradutor cultural" nos processos judiciais envolvendo minorias étnicas. Esse tradutor seria um profissional, em geral, um antropólogo, capaz de fazer compreender ao juiz e às demais partes do processo o contexto sociopolítico e cultural daquele grupo. "A ausência de profissional capaz de estabelecer diálogo intercultural faz com que o sistema judicial ignore a diversidade cultural e aplique o direito sempre do ponto de vista étnico dominante", destaca. 
e agora moram em uma casa de alvenaria, perto da cidade, não têm o que reclamar'. Ou seja, há, a priori, desvalorização de certas culturas. Parte-se da idéia de que a pessoa deveria tornar-se mais feliz porque the foi construída uma casa de material melhor, mas há uma dimensão da vida pessoas que não é puramente material, calcada nas relações que se estabelecem naquele grupo e com o lugar onde moram. Elas sabem se a vida delas melhorou ou não, mas esse saber não é levado em conta. Outro exemplo: há um grande número de trabalhadores em situação análoga à escravidão que são resgatados e sensibilizados sobre sua situação, mas voltam a essa condição. Por quê? Em parte, porque a conversa que se têm com esses trabalhadores não leva em consideração seus valores. É o caso dos indígenas do Mato Grosso do Sul que eram levados para os canaviais de São Paulo. Os índios não consideravam isso ruim, pelo contrário. Eles têm um rito de passagem em que é importante vencer obstáculos e eles vão por iniciativa própria. Não basta, assim, dizer-lhes que o trabalho escravo é crime, eles têm de compreender esse fato e empoderar-se. As políticas públicas que não analisam a prática cultural correm o risco de fracassar. O respeito à individualidade, às diferenças é fundamental. Isso exige a criação de serviços públicos diferenciados, tendo em vista que o modelo de cultura hegemônica esgotou-se. É preciso, assim, lembrar de trazer o destinatário da política pública ao processo decisório e saber que tornar o cidadão mais feliz tem de ter alguma relevância para a política pública”.

\section{O direito das pessoas comuns}

"Os direitos culturais constituem, a meu ver, o elemento-chave para que as políticas públicas direcionadas a atender os direitos econômicos e sociais sejam bem sucedidas. Hoje, na configuração dessas políticas, os modos de pensar, fazer e viver das pessoas não são valorizados e elas acabam sendo uma imposição de regras e soluções. $\mathrm{Na}$ coordenação da $6^{a}$ Câmara, lidei com questões envolvendo indígenas resultantes da construção da usina elétrica de Cana Brava, em Goiás. Na Procuradoria dos Direitos do Cidadão, lido com questões trazidas por pessoas que não são nem indígenas, nem quilombolas, mas pessoas comuns, que trabalham na terra, que buscam respeito aos seus costumes. Aqui, as maiores reclamações dizem respeito ao atendimento da educação, saúde e previdência. Observa-se, nessas questões, que muitos conflitos têm origem na falta de habilidade do administrador para conversar com o cidadão, em especial o mais pobre, o mais simples, os que vêm de outra cultura. Estou convencida de que grande parte dos atritos surgem dessa falta de comunicação. Eu vejo que mesmo as mudanças incorporadas pelo desenvolvimento do governo eletrônico atropelam, de certo modo, as pessoas. É uma modernidade que não chega à pessoas mais simples, uma cultura que se impõe sobre a outra, que exclui a outra, quando a idéia é que ela traga felicidade".

\section{Sensibilização}

"Para os procuradores, oferecemos um curso de uma semana sobre o tema. Mas não basta, em cursos, seminários ou treinamentos relatar o direito, a violação, etc. Em um grande grupo, apenas uma minoria vai levar em conta isso. A grande maioria vai ouvir, mas não vai incorporar essa dimensão na sua prática. É preciso colocar-se no lugar do outro. O procurador, o servidor público tem de sentir-se com aquele problema. Por 


\section{Comissão especial estuda populações atingidas por barragens}

O Conselho de Defesa dos Direitos da Pessoa Humana, órgão colegiado vinculado à Secretaria Especial de Direitos Humanos da Presidência da República, instituiu, em 2006, uma comissão especial com o objetivo de acompanhar denúncias de ocorrências de violações de direitos humanos decorrentes da construção de barragens e apresentar propostas para a prevenção, avaliação e mitigação dos impactos sociais e ambientais da implementação dessas barragens, bem como a preservação e reparação dos direitos das populações atingidas.

Um de seus relatórios mais recentes expõe a situação dos atingidos pela Barragem de Acauã, na Paraíba, inaugurada em 2002, destacando a degradação social da população afetada pela obra. "Os atingidos foram obrigados a mudar seu modo de vida: saíram de uma vida tradicionalmente rural para um meio 'urbano' (sem a estrutura de uma aglomeração urbana). Não há terras agricultáveis, nem terrenos que permitam a criação de animais. As famílias nada produzem. Não há alternativas de trabalho para esses cidadãos de pouca instrução, totalmente adaptados à vida no campo". O relatório aponta ainda a perda do acesso à água. As famílias, que antes tinham cisternas, açudes ou captavam a água do rio, passaram a depender de um precário sistema de captação e distribuição de água.

Fonte: Relatório das atividades de visita ao Estado da Paraíba e aos assentamentos decorrentes da implementação da barragem de Acauã. Disponível em: <www.mabnacional.org.br/materiais/ relatorioemergencial_acaua.doc $>$. onde começar para que questões transversais como gênero, raça, entre outros, passem a integrar a rotina? No Ministério das Minas e Energia, por exemplo, existe um comitê de gênero ${ }^{1}$, ou seja, um grupo de pessoas foi destacado para provocar e propor medidas no sentido de oferecer a homens e mulheres as mesmas oportunidades. Em outros lugares, o mesmo ocorre com relação a questões relativas à igualdade étnico-racial, ao acesso aos deficientes, etc. Aos poucos, essa preocupação se torna comum. É necessário também procurar compreender o outro. Nos processos penais envolvendo indígenas, principalmente quando são autores do crime, vê-se que o próprio Ministério Público e o Judiciário não conseguem perceber uma característica cultural do índio, o sentimento de pertencimento à coletividade que é muito maior que o nosso. Nos modos de ser dos índios os vínculos coletivos são muito estreitos e fortes, o que acontece com um, acontece com toda a tribo. Quando há crime, a tribo pune por exemplo, um tipo de pena muito presente entre eles é o banimento -, mas essa forte não é considerada. O que poderia ser feito? O Judiciário poderia considerar que não houve crime, poderia reduzir a pena, poderia entender que aquela pessoa já foi punida. Poderia também afastar um crime quando aquela ação é plenamente justificada pelas regras de comportamento daquele povo indígena, algo que não ocorre hoje".

\section{Notas}

* Reportagem realizada com base na entrevista feita com a Dra. Ela Wiecko, no dia 16 de maio de 2007.

${ }^{1}$ Comitê Permanente para as Questões de Gênero do MME e Empresas Vinculadas, estabelecido em maio de 2004. 